\title{
Unsettling SpongeBob and the Legacies \\ of Violence on Bikini Bottom
}

Holly M Barker

\begin{abstract}
Popular culture influences the ways that millions, and perhaps billions, of people worldwide think about the word "bikini." Consumers of popular culture likely associate "bikini" with the bathing suit, and those who watch the cartoon SpongeBob SquarePants encounter Bikini Bottom as the aquatic home of the eponymous bright yellow sponge and his friends (Barker 20I8). Stephen Hillenburg, the creator of SpongeBob, passed away in 2018 , a year that extended the cultural tsunami of his creations to even larger audiences and wider public acclaim than ever before, including a Tony Award nomination for SpongeBob SquarePants: The Musical (2016). Social media lit up with messages about Hillenburg's passing, noting it as a sad day for Bikini Bottom and fans of the show. Missing from the obituaries and tributes to Hillenburg's legacy, however, was any discussion about the normalization of colonial and military violence engendered through his cartoon depiction of Bikini Bottom. Despite being presented as a nonsensical and harmless cartoon, SpongeBob shapes global perceptions of the actual place called Bikini. The cartoon desensitizes viewers to the violence of settler colonialism, normalizes and erases the displacement of the Bikinian people from their ancestral land, and whitewashes US military rampages on the islands in the history and narratives of Bikini. It renders a particularly pernicious harm on Marshallese women, who are frequently both sexualized and erased (Teaiwa 20I0; Arvin, Tuck, and Morrill 20I3), through the cartoon's appropriation of their homelands. The settling of SpongeBob SquarePants and his friends into Bikini Bottom is connected to broader entanglements of military colonialism in the Marshall Islands that include dispossession from and destruction of the land, exploitation of the people and their resources, and an othering of the Bikinian and Marshallese people.
\end{abstract}

The Contemporary Pacific, Volume 31, Number 2, 345-379

(C) 2019 by University of Hawai'i Press 
Seeking to address these erasures and displacements, this article examines the symbolic erasure of the real-life people of Bikini Atoll through SpongeBob and considers the costs of maintaining a singularly submerged viewpoint that disconnects the lagoon bottom from holistic Marshallese constructions of place, which, rather than seeing the air, land, and sea as separate domains, as represented in the cartoon, maintain the interconnectivity between these realms. The discussions that follow disrupt the normalization of violent settler behavior in Oceania by exposing the ways that SpongeBob's encroachment on Bikini Atoll maintains an American military hegemony that erases intergenerational violence against the Marshallese people.

I argue that despite the settling in of SpongeBob on the bottom of Bikini's lagoon, which effectively removes our gaze from the Bikinians living within the context of their land and seascapes, the Marshallese people assert their presence in the face of settler colonial efforts to "eliminate the native" (Wolfe 2016) by consistently incorporating the bottom of the lagoon into their cosmologies and the domain of the Bikinian people on the surface. A diverse array of Marshallese cultural practices-including language, storytelling, weaving, and the sailing of outrigger canoes-embody the strength and resilience of the Marshallese people, who endured the equivalent of nuclear war on their islands and transmit their resilience to successive generations. ${ }^{1}$

\section{Insinuation as a Form of Resiliency: Bikini BotTom Is Not a Fictional Place}

Oceanian scholar Vicente Diaz acknowledged the tenacity and resilience of Pacific Islander culture and its ability "to reclaim a space for itself even if it must insinuate itself within the stories of others who have come to the island for their own interests and machinations" (200I, I75). This idea is intriguing to consider as it applies to the people of Bikini Atoll in the Republic of the Marshall Islands and the possibilities that Bikinians envision and enact for reclaiming space. As Diaz noted, "Indigenous culture and history and memory occur in and on (and even against) terms established and maintained by American hegemony as manifest in postwar discourses" (200I, I75). As I will discuss, Marshallese maintain numerous cultural forms that reclaim ancestral connections to spaces American postwar discourse attempted to eradicate by designating the area as the "Pacific Proving Ground," a phenomenon that lingers through the settler 
existence of SpongeBob on Bikini Bottom. Together, Marshallese culture, history, and memory work against the global phenomenon of SpongeBob, demonstrating "enduring indigeneity" and Marshallese intentions to "exist, resist, and persist" (Kauanui 20I6).

Russell Hicks, Nickelodeon's president of content development and production, boasted that "the show airs in 170 countries, and they tell me that every half second, somebody somewhere in the world is interacting with SpongeBob in one way or another. Every half second! It blows my mind. ... And it's not just the 75 million Facebook likes or the I million followers on Twitter. SpongeBob gets around. He's played soccer with Michelle Obama and David Beckham, and brightened up Pharrell's feet. Not bad for an invertebrate, right?" (quoted in Beck 20I3, II). Hicks was correct that SpongeBob, his quirky friends, and the other residents of the fictional town of Bikini Bottom have achieved massive global recognition. In sharp contrast to the pervasiveness of the American hegemonic discourse of SpongeBob, people worldwide know little, if anything, about the nonfictional residents of the real-life Bikini Bottom, or Bikini Atoll.

For SpongeBob audiences, Bikini Bottom appears as an amalgam of token objectifications of Oceania; it is a place where characters reside in buildings shaped like pineapples, Easter Island statues, and tikis and are surrounded by Hawaiian-shirt motifs and steel-guitar music. ${ }^{2}$ This cultural appropriation of iconic Pacific Island representations is not a new practice, as can be seen across every facet of global popular culture, including restaurants, hotels, cocktails, film, literature, and video and board games (Beck 20I3). These practices allow the specificities of Pacific Islanders to go unmarked and unaddressed (Teaiwa 2010; Diaz 2002), reducing the cultural diversity of Oceania to symbols of tourist engagements with the islands (Kahn 20 I I). Native Hawaiian filmmaker Anne Keala Kelly called the removal of Pacific Islanders from representations of their own cultures "the narrative equivalent of ethnic cleansing," in which people get erased from their own storylines (quoted in Herreria 20I7). This erasure of the people from their own storylines is evident in the case of Bikini Atoll. The violences against Bikinians are not common knowledge outside of Oceania, as the world's collective stories and histories about World War II and its aftermath in Oceania frequently focus on the engagements of military powers at places like Pearl Harbor, Nagasaki, and Hiroshima but fail to acknowledge the experiences of Pacific Islanders like the Bikinians (see Camacho 20II). 


\section{The Violent Appropriation of Bikini}

During World War II, US troops engaged in protracted combat to expunge Japanese soldiers from the Marshall Islands (Camacho 20II; Falgout, Poyer, and Carucci 2008) and, with the assistance and support of Marshallese scouts, defeated Japanese forces. Like Japan, the United States recognized the strategic value of an outpost in the northern Pacific Ocean, west of Hawai'i and east of Asia. In the reordering of world governance that took place after the war, the US government convinced the United Nations to give it administrative authority for an area that colonial powers carved out of Oceania and designated as Micronesia, ${ }^{3}$ including the Marshall Islands. With the blessing of the United Nations, US settler colonialism began (Wolfe 2006; Veracini 20I0). American settlers-primarily military but also non-military government contractors and their families (Dvorak 2018)-laid claim to the Marshall Islands as transient, but consistently aggressive, influences on the islands. The US government established the structures of settler colonialism, as described by J Kēhaulani Kauanui (20I6), through a permanent base on Kwajalein Atoll, today known as the Ronald Reagan Ballistic Missile Test Site, where it destroys, erases, and replaces Marshallese renderings of place with the construction of institutions, names, and practices that privilege colonial objectives. Military leaders and their families come and go on Kwajalein, but from the base, they coordinate and maintain control of Marshallese land, air, and sea to enact US military objectives. ${ }^{4}$

Once established on Kwajalein, the US government unfolded its plans for Cold War nuclear weapons experimentation in the islands. As a form of settler colonialism, in which imperial powers settle into new locations to enact dominance (Wolfe 2006), the predatory, nuclear, and military colonialism spread its violence to Bikini, Enewetak, and other communities. The US government removed the people of Bikini and Enewetak Atolls from their ancestral islands to conduct top-secret military detonations and experiments, documenting the human and biological impacts of radiation exposure (Barker 20I3; Johnson 20I3; Horowitz 20II; Johnston and Barker 2008; Niedenthal 200I).

Bikini, the first site chosen by the US Navy as a ground zero for weapons testing, became a global phenomenon long before SpongeBob. French designers of new post-World War II swimwear regaled the splitting of the bathing suit into two pieces, similar to what scientists did with the atom to provide energy for the atomic detonations that took place on Bikini 
(Barker 20I5). At the time, the bikini reflected the Western world's ability to resume leisure activities, such as spending time at the beach, and its post-World War II love affair with the weapon credited with defeating the Japanese.

The frivolity associated with the bikini certainly does not characterize the firsthand experiences of the Japanese and Marshallese people who understand the genocidal nature of these weapons designed for mass destruction. The bikini emerged from a twelve-year firework display of US military superiority above, below, and on Bikini and Enewetak atolls-all of the domains that make up the Marshallese notion of place. The United States detonated sixty-seven nuclear weapons in the Marshall Islands from I946-1958, including the I March 1954 Bravo detonation on Bikini Atoll, a thermonuclear explosion that was the equivalent of one thousand Hiroshima-sized bombs. The bikini thus became the first global disassociation of Bikini from this violence: It deflected gazes from the vaporizing of entire islands and the banishing of countless generations of Bikinians from their ancestral home. In a similar way, SpongeBob shifts viewers' contemporary gaze from the Bikinian people who live on the surface of the islands, or the bikini top, to Bikini Bottom, the lower portion of the bathing suit, or the proverbial backside.

The symbolic violence of SpongeBob's setting in a place called "Bikini Bottom" threatens to erase the cultural meaning of the surface of the coconut to the Marshallese. "Bikini" is the anglicized word for "Pikinni," or "surface of the coconut," in Marshallese ("pik" means "surface" and "ni" means "coconut"), ${ }^{5}$ and Marshallese culture, like other Oceanian cultures, places great value on this part of the coconut. While a tourist encountering a coconut while on vacation or even in a grocery store might think of the surface of the coconut as unimportant and dispensable, for the Bikinian people, the hair attached to the outer part of the coconut is a building block for a community, not a disposable item. Marshallese have traditionally rolled that hair into the sennit that hoists and holds the sails and binds the hulls of canoes, allowing some of the best navigators in the world, including the Bikinians, to navigate ancient oceanic pathways by reading minute, barely perceptible wave patterns (see Genz 20I 8; Genz and others 2009). The sennit also hugs together the materials for cultural fortitude, such as buildings, tools, dance implements, and clothing. The surface of the coconut is essential to a resilient Marshallese culture that continues to thrive today despite four centuries of colonial onslaught, including twelve years of military experimentation to perfect nuclear weapons. There is no 
greater testimony to the resilience and fortitude of the Marshallese than the ability to endure repeatedly a weapon of mass genocide-a device with the potential to extinguish all life on this planet. Weapons of mass destruction cannot make the Marshallese disappear, nor can SpongeBob.

\section{How Is This History of Nuclear Testing Incorporated into SPongeBob SquarePants?}

Online discussions of fan theories abound regarding the "true meaning" of SpongeBob (FrancisDollarHyde 2012; Bradley 2015). For example, there is speculation that the seven major characters of the show represent the seven deadly sins: the amorous SpongeBob represents lust; Krusty Krab, the money-loving owner of a hamburger joint, personifies greed; and Patrick Star, the large, pink sea star, embodies sloth. Another popular theory-one more closely related to this article-suggests that the characters in the show are malformed and bizarre because they are mutants exposed to radiation from the atomic detonations at Bikini, and characters like Sandy Cheeks the squirrel don diving suits and masks to stay safe from the radiation.

This second fan theory is not farfetched, given the insertion of liveaction footage of detonations at Bikini Atoll into the franchise's television programs and movies. However, the point of this article is not to support fan theories or to expose the intentionality of the show's creator. Regardless of Hillenburg's original motivations for the cartoon, SpongeBob's squatter existence at Bikini enables a powerful media influence to lay claim to and settle into Marshallese lands. SpongeBob's assertion of residence as part of fictional entertainment suggests that the United States' taking of Oceanian land is natural and even comical. The real-life story of Bikini evokes tears and anger from the people who fail to come into focus in SpongeBob's storyline, in which the fictional Bikini Bottom serves as a mirage that clouds viewers' ability to see and acknowledge the nonfiction reality. Kelly opined about this kind of disassociation created by the media: "The tough part is that most people would give a damn. Most people would care if they heard the truth. Most people do care about justice, ... but they're being entertained into not caring about it" (quoted in Herreria 2017). In this regard, by separating the human tragedies of Bikini from the atoll's media representation, SpongeBob diminishes opportunities to create viewer empathy and understanding about the plight of the Bikinians. 
Although the US government removed the people of Bikini from the atoll above the surface, this does not give license to SpongeBob or anyone else, fictitious or otherwise, to occupy Bikini. SpongeBob's presence on Bikini Bottom continues the violent and racist expulsion of Indigenous peoples from their lands (and in this case their cosmos) that enables US hegemonic powers to extend their military and colonial interests in the postwar era. However, in order to dismantle hierarchies of oppression, including in its popular culture forms, it is necessary to amplify Marshallese notions of land.

\section{MARShallese InSISTENCE ON AN INTERCONNECTED NOTION OF "LAND"}

The everyday rhythms of life on coral atolls underscore a Marshallese vision of interconnected domains, including areas below the sea. Like marine biologists observing, gaining knowledge of, and acting on theories about sea-based life, the Marshallese envision the domains of sky, land, and sea, including areas below the sea, as intertwined; they recognize that their lives on the surface of the islands are possible because of the skeletons of marine invertebrates growing on top of submerged volcanoes. The lagoon, with its quiet waters surrounded by a ring of islands, is at the heart of Marshallese community life. Given Marshallese worldviews and notions of the land, sea, and sky as interrelated and symbiotic, it is hardly surprising that Marshallese mythology, like stories from across Oceania, tell of fishermen who snag giant islands from below the surface, pulling them above the water so that humans can create their homes.

Numerous Marshallese origin stories exist that describe the emergence of both humans and deities from the heavens and the seas (Tobin 2002), such as the legend of Wullep, the first deity who emerged from a giant clamshell from the depths of the ocean (Erdland I9I4, 3IO-3II). The interconnectivity of the Marshallese world is paramount in the atoll environment that SpongeBob tries to parcel into distinct sections. The terrestrial and marine interweaving is a central component of the legend of $\bar{A}$ jinkōj Eo (The Gifts), first published in 1976 during US occupation of the islands. ${ }^{6}$ In the story, fishermen search for food to feed the hungry people, ultimately pulling in a giant island filled with food-bearing treesliterally gifts that emerge from beneath the seas. The story, as well as the accompanying illustration by Marshallese artist Iso Lañinbelik (Gideon 20II, 95; see figure I), reinforces an insistence on reaffirming a Mar- 


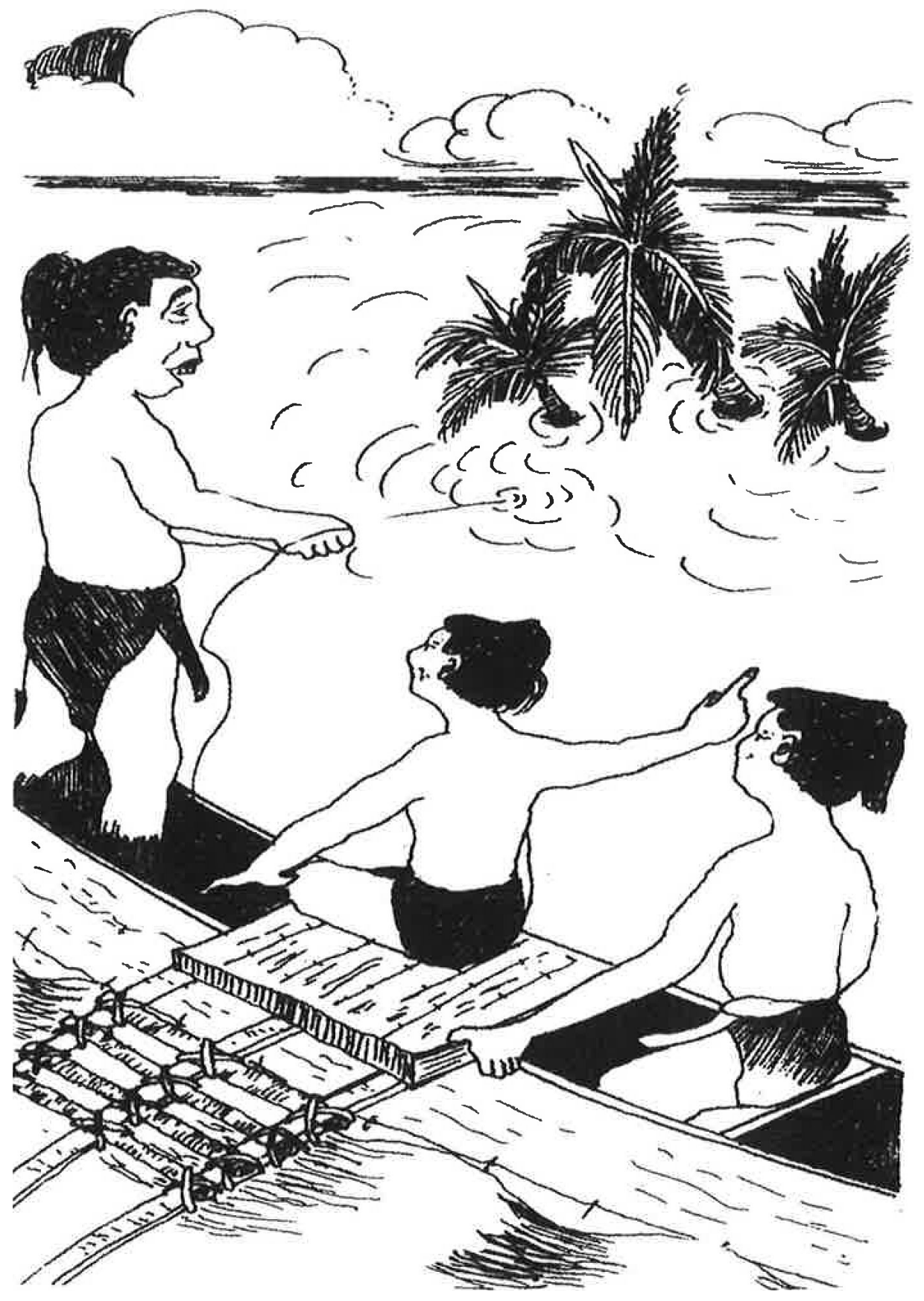

FIgURE I Artwork by Iso Lañinbelik depicting Marshallese stories about the islands and terrestrial life emerging from the sea. Reproduced with permission of the Instructional Services Center, Marshall Islands Ministry of Education. 
shallese worldview that emphasizes the interconnectivity that SpongeBob bifurcates.

The concept of "land" is a Western construction that does not equate with a traditional Marshallese worldview; one's land is not simply dry acreage to stand on, and it certainly is not a commodity that any one person or generation can own (Johnston and Barker 2008). The Marshallese call their world—again, not just the land—“aelōn kein ad," frequently translated as "these islands of ours." Sometimes Marshallese refer to their nation, the Marshall Islands, as "Aelōn in Majol," a vestige of colonial naming practices honoring the initial "discoverer" of the location, British Captain John Marshall. Despite the similarities in sound, "island" is not a translation for "aelōn" (pronounced long-i sound + luhng); the word "island" focuses on the terrestrial realm above the ocean and does not capture the expansive Marshallese version of place embodied in "aelōn," in which "ae" refers to the currents or the seas and "lōn" to the heavens or the skies above (Ahlgren 20I6). As the concept of aelōn communicates, there is no separation of realms because Marshallese notions of land are expansive and holistic, extending to the bottom of the ocean and lagoons, as far as the ocean currents flow, and as high as the stars and heavens. ${ }^{7}$

In addition to the volcanoes that support coral and human life, atolls throughout the Marshall Islands include prominent seamounts, or underwater mountains that are rooted to the seafloor and do not reach the surface. There are forty-three seamounts in the Marshall Islands, which have proper names identifying them as important cultural features that connect to the daily lives of people on the surface (Johnston and Barker 2008, 69). At Bikini, as with every atoll of the Marshall Islands, the multidimensional cosmos maintains the relationships between lagoon, land, and air. Bikini Atoll comprises the skies above, the seas and currents around, and the volcanoes and lagoon below, including Bikini Bottom, where the colonial squatter SpongeBob and his friends reside. Unlike in the cartoon, the bottom of the lagoon remains actively joined with Marshallese daily life on the surface, as is evident in the language, mythology, and Lañinbelik's artwork.

\section{Songs and Place}

Song is another medium through which Marshallese assertions of their own history and memories of place challenge any efforts to usurp people from their lands. Imagine the silence that would emerge from asking a 
room full of young people to discuss their knowledge about US activities on Bikini Atoll. Now imagine the voluminous response you might receive to the lead question in the SpongeBob theme song: "Who lives in a pineapple under the sea?" (Waller 20I0). This discrepancy should be unsettling to everyone.

In the theme song, the songwriters, including Hillenburg, ask kids if they are ready to sing along, or, put another way, to join the community of SpongeBob fans. The first act of the song is to have children identify who resides in the pineapple house. The children's response, repeated extensively throughout the song, affirms that the house and Bikini Bottom are the domain of SpongeBob. The song's directives, ensconced in humor, provide the viewer with an active role in defining Bikini Bottom as a place of nonsense, as the audience is instructed, "If nautical nonsense be something you wish ... drop on the deck and flop like a fish" (Waller 20I0). The viewer becomes an unwitting participant in the co-opting of Bikini's story and the exclusion of the Bikinian people from the postwar discourses that Diaz illuminated (200I).

It is implausible that Hillenburg and Nickelodeon, the cartoon's network, envisioned an act of US colonialism as they developed the show, but it is disturbing that it did not occur to them that Bikini Bottom and Bikini Atoll were not theirs for the taking. Since millions of viewers worldwide hear about Bikini Bottom through SpongeBob without being offered a deeper understanding about Bikini Atoll or its people, it is essential to consider how the show shapes viewers' worldviews, ideologies, and understandings. As critical media scholar Stuart Hall noted: "In modern societies, the different media are especially important sites for the production, reproduction, and transformation of ideologies. . . Institutions like the media are ... part of the dominant means of ideological production. What they 'produce' is, precisely, representations of the social world, images, descriptions, explanations and frames for understanding how the world is and why it works as it is said" $(2003,90)$. In line with Hall's ideas, millions of children who view the show become acculturated to an ideology that includes the US character SpongeBob residing on another people's homeland as a framework for how our world operates. A colonialism that settles SpongeBob and his friends into Bikini Bottom is thus produced, reproduced, and normalized through the cartoon series.

The SpongeBob theme song stands in stark contrast to the song "Bikinian Anthem," which was written in 1946 by a member of the Bikini community, Lore Kessibuki. It expresses Kessibuki's “overwhelming” feeling 
and "great despair" of being ripped away from his home islands as an immense power destroys the tranquility of life on Bikini. The song remains a staple at annual commemorations of the nuclear legacy on the I March anniversary of the Bravo detonation, reaffirming the memories and history in Marshallese terms and often accompanying a multitude of tears. The anthem is sung in Marshallese government buildings; on the islands of Kili, Ejit, and Majuro, where the community resides; and in Fayetteville, Arkansas, Salem, Oregon, Enid, Oklahoma, and other locations in the United States where the community's fragmentation and migration serve as constant reminders of the violent separation of the people from their land. All of this is embodied in the song:

Bikinian Anthem

No longer can I stay; it's true.

No longer can I live in peace and harmony.

No longer can I rest on my sleeping mat and pillow

Because of my island and the life I once knew there.

The thought is overwhelming

Rendering me helpless and in great despair.

My spirit leaves, drifting around and far away

Where it becomes caught in a current of immense power-

And only then do I find tranquility.

(quoted and translated in Niedenthal 200I)

Kessibuki's creation emotes and documents the Bikinian people's hardships and strongly refutes any American hegemonic efforts to erase or cleanse the atoll of US sins. For Kessibuki and the Bikinians who have continued to sing the anthem since his death, leaving Bikini was akin to ripping the soul of the people from their bodies, as their islands and the life they once knew were gone. In an interview with Jack Niedenthal, Kessibuki recalled his motivation to compose the song, which came on an extremely challenging day for the Bikinians, who were experiencing near starvation after their forced relocation from Bikini:

I vividly remember that one day many of our people were walking around vomiting, and having a terrible time with their stomachs, because they had forced themselves to eat a lot of the poisoned fish. These fish were the only available food for us to eat at the time. It was mid-afternoon and extremely hot when I myself felt nauseated and I slowly slumped to the ground beneath a coconut tree. All of a sudden, a burst of images rushed into my mind about Bikini. I recalled the memories of what wonderful lives we had lived when we were on our islands. It was at that moment that I began to compose a vision in 
my soul about my homeland-Bikini, Bikini, Bikini, Bikini-the dream was so beautiful: I remembered the endless, white beaches where I used to take long walks with the sands rising up between my toes; and I thought about the lush jungles that had provided me with countless adventures as a child; and I tasted the delicious fish that could be easily caught—even by a small child - in the lagoon; and I imagined myself touching the tombstones in the graveyard of the elders; and I envisioned myself sailing across the lagoon in a canoe which was loaded down with fresh tuna; and I recalled how I used to talk with my family, peacefully and quietly, long into the night. These recollections caused me, when coupled with my weakened state, to become quickly, and embarrassingly, reduced to tears right there under the tree-in the daytime! I was supposed to be a leader, yet, I was crumbling, crying. My god, I thought, was I losing my mind? That was when I began to construct a powerful song that seemed to flow out of the depths of my being. My mouth felt like it was uttering the words on its own, as if they were coming from an unknown source. (quoted in Niedenthal 200I, I37-I38)

The nuclear songs of the Marshall Islands communicate experiences that are in many ways beyond comprehension (Schwartz 20I2). When the Bikinians sing their anthem as a collective, they call attention to the profound pains of nuclear colonialism that have been rendered invisible through global discourse, including through television shows like Sponge$B o b$, that erases US violence and the hardships of the Marshallese people. Kessibuki's song makes the inaudible audible (Schwartz 20I2, I4). While SpongeBob gets children to laugh and imagine wriggling around like fish, contemporary singing of "Bikinian Anthem" ensures that the histories and narratives of the community remain firmly entrenched in the lives of the Marshallese people. At the same time, songs like the anthem garner tears and articulate the continued traumas residing in the community; they carry the history of the people as they are taught to children and passed to successive generations of Bikinians and Marshallese.

People do not laugh at the SpongeBob theme song and cartoon because they are malicious or willing conspirators to colonial activities. Like the bikini, the program obfuscates the historical and contemporary pain of the Bikinians by cleansing them from their own story and place. However, if the laughter of audiences is not wrong, then neither are the tears of the Bikinian people. What should give us pause is the infinite gulf between these reactions, a distance as vast as the comfort zone the US government constructed between its weapons-testing program in the Marshall Islands and the American public. Except for extreme fans exploring creation theo- 
ries, consumers of SpongeBob do not think about the nonfictional Bikini, and online fan sites do not mention the Bikinians or their experiences. Likewise, in the Marshall Islands and in Marshallese communities across the United States, it is extremely rare to find conversations about the show and its connection to the people's history. ${ }^{8}$ Given the hypervisibility of SpongeBob juxtaposed against the almost invisible existence of the Bikinians, the potential to create empathy and understanding in the cartoon's audiences and to educate them about the history of the Bikinians' erasure remains untapped. ${ }^{9}$ However, educational efforts can illuminate Bikinians' constant connection to their homeland, even in diaspora. Though Bikini is unpopulated because of lingering radiation, it is far from a wasteland.

\section{The Language of Wastelanding and Erasure in SpongeBob SquarePants}

In her documentation of the impacts of uranium mining on Navajo communities, Traci Brynne Voyles described the concept of wastelanding, in which the racialized bodies of Indigenous people become removable and expendable. Locations such as Bikini Bottom "are marked, physically and ideologically, for exploitation, resource extractions, and national sacrifice" and ultimately "rendered pollutable" (Voyles 20 I 5, I 5).

Voyles's description is fitting for the activities that transpired on Bikini Atoll, where the US Navy framed a request for the people to vacate their islands as being "for the good of mankind." The United States presented concepts of nuclear deterrence to the Marshallese and asked the Bikinians to play their part so that the United States could cultivate a weapon that would produce world peace (Weisgall I994; Niedenthal 20I2; Barker 20I3; Horowitz 20I I). ${ }^{10}$ Anthropologists Laura Nader and Hugh Gusterson identified the externalization of harms as an essential feature of nuclearity, or the imperial control of the nuclear industry to maximize political, economic, and military benefits for colonial powers (2007). By externalizing the violence of nuclear weapons, colonial powers deploy devices of genocide that would otherwise seem unimaginable when considering the good of humankind (Nader and Gusterson 2007). In the case of the Marshallese, the US government secured all the benefits of nuclearity, including military dominance, Cold War political power, and scientific and military advancement. The Marshallese, however, experienced the opposite of world peace, as people had their bodies, culture, economy, and lands ravaged by the weapons-testing activities (Johnston I994; Barker 20I3). 
SpongeBob contributes to the wastelanding of Bikini Atoll through a multimodal construction of ideologies, including the discourse, music, visuals, and depictions that operate synergistically to construct meaning about Bikini Bottom and those who inhabit it. ${ }^{11} \mathrm{~A}$ fan page devoted to the show reveals how the public assigns meaning to SpongeBob, including representations of the Marshallese as primitive and extinct, as evident in a discussion about an episode depicting ancient sea caves containing rudimentary drawings, "probably drawn by prehistoric Bikini Bottom citizens" (Encyclopedia SpongeBobia 20I7). The Bikinian people lived on that atoll and lagoon for centuries before their sovereignty and bodies became expendable to US military and political interests, but as Diaz noted (200I), the tenacious resilience of Oceanian history and culture remain affixed to the discourse even when these renderings are faint references to a previous life reflected in sea-cave drawings.

The characters who moved to Bikini Bottom after the Bikinians had been removed by the United States surf and swim at Goo Lagoon, a place made of a "strange goo" (Encyclopedia SpongeBobia 20I7). In nonfiction, photographs from the postwar era show US servicemen enjoying the beauty of Bikini Atoll before it became too contaminated with the radioactive materials, or strange goo, that render it unsafe for human habitation today. In her poem "History Project," Marshallese poet Kathy Jet"nil-Kijiner articulated the devastating emotions and realities clinging to the background of American engagement in the islands. As Kessibuki did decades before, Jet nil-Kijiner described her reaction to photographs she encountered while doing research for a nuclear-themed history project as a teenager:

I flip through snapshots of american marines and nurses branded white with bloated grins sucking beers and tossing beach balls along our shores and my islander ancestors, cross-legged before a general listening to his fairy tale about how it's for the good of mankind to hand over our islands let them blast radioactive energy 
into our sleepy coconut trees

our sagging breadfruit trees

our busy fishes that sparkle like new sun

into our coral reefs

brilliant as an aurora borealis woven

beneath a glass sea

God will thank you they told us $(2017,2 \mathrm{I}) .^{12}$

Most framings of American history exclude the Bikinian and Marshallese people so effectively that the beaches of the ground-zero locations become visible only as playgrounds for servicemen. With the introduction of radiation from the detonations, the US discourse shifts to a place of strangeness and weirdness, the fabric of SpongeBob. When asked by the Huffington Post what fans could expect in the 2015 SpongeBob SquarePants movie, Tom Kenny, the voice of SpongeBob, replied: "It's a movie that goes out of its way to be strange and weird, which is what I love. You know, everything I loved as a kid was strange and weird. Everything my kids love, they tend to go for the strange and weird" (quoted in Bradley 20I 5). While describing a book designed for super fans of SpongeBob, Kenny purposefully conjured Bikini Bottom as a place of weirdness and oddness: "Much like this book you're holding, this SquarePantsian world I live in is chock-full of odd little pockets and flaps with weird stuff inside them that I'm still discovering. . . . So on behalf of Team SpongeBob, we hope you enjoy this glimpse into our subaquatic archives-these rare bits of graphic flotsam and jetsam dredged up from the subcellar of the pineapple. In true Bikini Bottom fashion, they run the gamut from gorgeous to grotesque" (quoted in Beck 2013, 9).

The rendering of Bikini as a place not fitting for humans normalizes the situating of strange characters below the surface. Kenny chose words such as "flotsam" and "jetsam" to describe Bikini Bottom, a place with detritus cast from ships, or the proverbial wasteland in Voyles's theory. The flotsam and jetsam in SpongeBob, presumably items like the life buoy inscribed with the words "Bikini Bottom" prominently featured in the show, reference the precariousness of life on Bikini's surface. These terms might also apply to the sunken ships that appear in many episodes, much like the Japanese and American boats that lie on the lagoon of Bikini today-relics of detonations to test the vulnerability of naval vessels to nuclear weapons (Weisgall I994). 
Global audiences have the privilege of laughing at the weird, strange, and odd world of Bikini because of its geographic and personal distance; the United States exported its most dangerous activities to Indigenous lands-the mining of uranium on Navajo and Spokane land, the processing of plutonium on Yakama, Nez Perce, and Umatilla land, and the testing of nuclear weapons on the land belonging to the Bikini and Enewetak people (Barker 20I 5). SpongeBob has the privilege, as an American character, of not caring about the detonation of nuclear bombs, as noted by one of SpongeBob's writers, C H Greenblatt: "I write SpongeBob as innocent, without irony, sarcasm, or ulterior motives. . . . The way I like to approach SpongeBob is that he gets excited about things that nobody generally gets excited about. Here's a guy who could get super-excited about a napkin but wouldn't care if there was an explosion outside" (quoted in Beck 20I3, 30). The detonations do not cause concern for the characters, as they did for the Bikinians, nor do they compromise SpongeBob's frequent activities, like visiting hamburger joints or the beach with friends. Doug Lawrence, the voice of another major character, Sheldon J Plankton, suggested that "SpongeBob is a character who represents one of the best aspects of the American Dream.... SpongeBob has got some kind of utopian version of life in his head" (quoted in Beck 2013, 33). This is similar to France's erasure of the Māohi people's experiences with nuclear weapons testing in French Polynesia, as noted by anthropologist Miriam Kahn. Kahn discussed the role of the tourist industry in creating narratives of pristine beauty that erase colonial violence and keep intact representations of islands as places to fulfill the dreams and needs of Western tourists (2OII). Mass media enables American and other audiences to remain oblivious to history and politics (Giroux 20I4). The public's privilege of ignorance, however, deepens the violence rendered against the Marshallese people and exacerbates the distance between "us" and "them."

\section{The IMPACT OF Othering AND Wastelanding THE Marshallese and THEIR Islands}

SpongeBob plays a role in othering and wastelanding the Marshallese people and their islands, but what impact does the cartoon have on the Bikinian people who are purposefully excluded from the American media discourse of the show? Can Bikinians access the utopian ideal that Doug Lawrence described? With SpongeBob and his friends deeply settled into territory represented as American, the Bikinians not only are extracted 
from their homelands but also become expendable when they legally enter US domains.

Most immigrants who enter the United States legally become eligible for government-subsidized support services, particularly those designed to serve low-income communities, such as Medicaid or Social Security. Marshallese, however, including the Bikini people and others forced from their home islands during the Cold War, do not. Through the Compact of Free Association between the United States and the Republic of the Marshall Islands, they have the political right to come to the United States to live, go to school, and work; they pay state and federal taxes, have US Social Security numbers, and pay into the US Social Security system; and they serve in every single branch of the US Armed Forces. However, despite these contributions, they are not eligible for many of the services they support. ${ }^{13}$

The experiences of Bikinian Lucky Juda underscore the US policy impacts of othering people, in this case by excluding Marshallese from benefits typically extended to US citizens and legal US immigrants. Juda was in utero when the US government removed the Bikini people from their land in 1946, and he grew up away from his home atoll, except for the time the US government prematurely resettled the Bikinians in the I970s. ${ }^{14}$

In 20I6, Juda and his wife left the Marshall Islands to visit their daughter, who legally resides and works in Washington State. Juda was in the Seattle area during the anniversary of the Bravo test, and he contacted the Burke Museum to request support to convene a communal gathering to ensure that the nuclear legacy remains understood by successive generations living in the diaspora. Following the solidarity event at the museum on I March, Juda spoke to Micronesian students at the University of Washington, explaining:

The whole Marshall Islands is condemned from the bomb. There are a lot of people that got sick... . Thyroid and cancer and a lot more... . Tumors. All kinds of sickness. It is very sad for all of us people of the Marshall Islands.... The Americans thought that we are just like the animals. We are guinea pigs.... These are some of the things that I think about every day. When I am thinking about all the things that are going on, I wonder: Why did God let me live? Why was I born when all of this is going on? I shouldn't have been born. I should have died at that time. (Juda 20I6)

Juda's deep despair, including his feeling that he should not have been born, echoes the sentiments in Kessibuki's song written sixty years earlier. 
The trauma of the Marshallese did not end with the cessation of the testing; historical trauma and chromosomal damage mark successive generations of people terrorized by US activities.

The United States' removal of the Bikinians from their home islands meant that Juda could not be born on his ancestral land, where he would have had access to the food, resources, and tranquility that Kessibuki described. He and his family still cannot return to Bikini because of the lingering radiation contamination-vital historical context that has been expunged from SpongeBob's stories of Bikini Bottom. Despite the many ways US government activities have affected his health, Juda was denied access to health care in Washington State when he became concerned about his heart during his visit. Since he could not obtain medical care in the United States, he and his wife hastened their return to the Marshall Islands. In transit, he suffered a heart attack in the Honolulu Airport. He was taken to a hospital but did not have medical coverage to stay for the recommended amount of time, so he returned to the Marshall Islands, a nation that struggles greatly to provide health care for its people. Juda's racialized, othered body, which was excluded from US health care and interpreted as outside the bounds of US responsibility, was and continues to be expendable to the United States. The nuclear weapons testing at Bikini was said to be for the good of mankind, but this does not include a racialized man like Juda. In this instance, the wastelanded body is otherized from eligibility for basic health programs. Suffering, othered bodiesbodies like that of Juda, whose first name becomes ironic-continue to be exterminated through the everyday practices of contemporary culture, such as SpongeBob.

With the distancing of the Marshallese people from our collective awareness, the American public becomes free to laugh or to focus their anger and concern elsewhere. For example, Americans became outraged when they saw photographs of US scientists strapping animals to the naval ships in Bikini's lagoon as subjects during the tests, as well as when they saw the post-detonation images of dead or mutilated livestock. In "History Project," Jetnil-Kijiner described her reaction when she learned about the American public's objections to this use of animals and their accompanying blindness to the reality of the Marshallese people and their hardships:

\section{At I 5}

I want radioactive energy megatons of tht and a fancy degree anything and everything I could ever need 


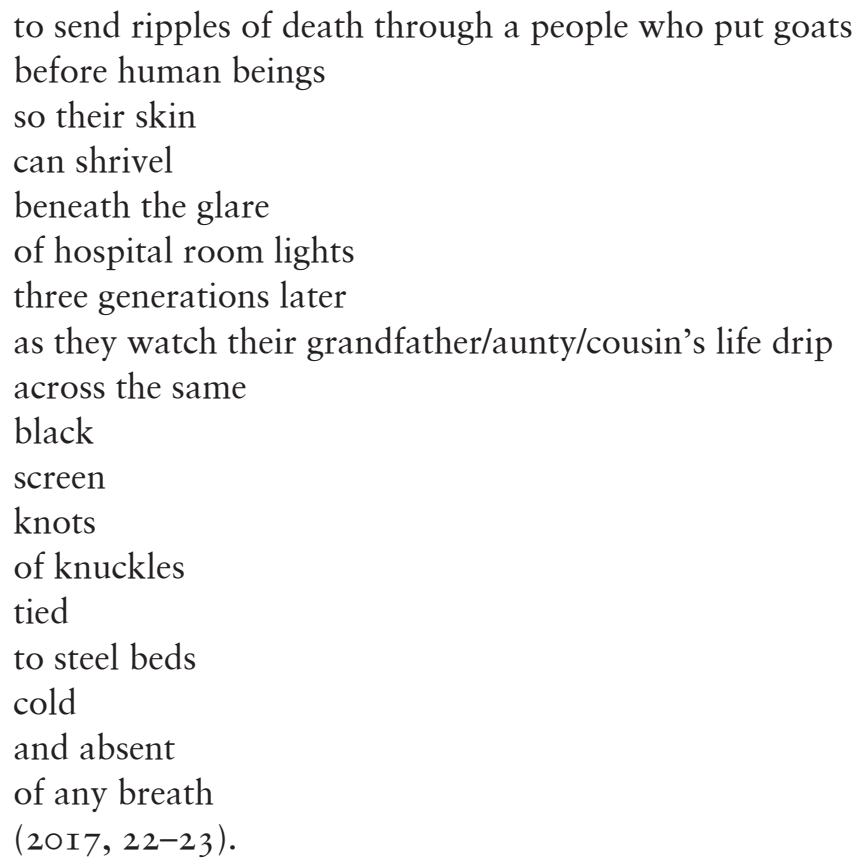

The impacts of excluding Marshallese from American thought and compassion play out regularly in the hospital rooms where Jetnil-Kijiner and others watch loved ones succumb to cancer or in the health-care centers that deny access to people like Juda. SpongeBob continues this pattern, in which Marshallese suffering is kept out of view. Maybe the ultimate privilege is not having to watch loved ones die from cancer and radiationrelated illnesses because the torturous outcomes of US activities unfold in the wastelanded, otherized domains of someone else's land and inside someone else's body. The Bikinians' continued diaspora in 2019 illuminates racist notions about whose land and bodies continue to be expendable to support American hegemonic interests.

\section{What Do Smokey Bear and SpongeBob SquarePants Have in Common?}

The wastelanding and othering of entire communities becomes an everyday and normalized practice through the use of seemingly harmless children's characters. The potency of cartoon characters cannot be dismissed as innocuous simply because children are the target audience; cultural violence, as with all forms of violence, becomes even more horrific when 
aimed at young people. SpongeBob's residence on Bikini Bottom is a form of symbolic violence, "an unconscious mode of domination subtly embedded in everyday thought, action and objects that maintains its power precisely because people fail to recognize it as violence" (Genz and others 2018). Similarities exist between popular culture's treatment of the Bikinians and their experiences and the creation of children's characters in New Mexico to conceal the violent takings of land. Jake Kosek highlighted the impacts of US Forest Service policies on displaced communities in northern New Mexico, where "land use practices and acquisition [are] inseparably tied to a cultural logic of exclusionary nationalism and racially violent practices" (Kosek 2006, 227). He examined the role of Smokey Bear, a character created by the US Forest Service to educate children about the importance of preventing forest fires, in both representing and reproducing hegemonic practices of land seizure, resource control, and exclusion. Kosek considered how this cartoon construction naturalizes the authority of US park rangers to assert government ownership of Indigenous land, as well as the policing of activities that best represent the United States' national interests (2006). This provides an interesting parallel to SpongeBob, as, like Smokey Bear, SpongeBob plays a role in creating an "exclusionary nationalism," which Kosek described as a nationalism that establishes parameters about ownership, residence, and acceptable activities on government-controlled land (2006, 209). The same exclusionary nationalism embodied in both Smokey Bear and SpongeBob is evident in Juda's inability to access adequate health care based on his immigration status.

Kosek demonstrated how Smokey Bear, in his role as an authority figure protecting the land, has "help[ed] to undermine the legitimacy of alternative land claims" and to preserve state authority to occupy and control $(2006,209)$. This can also be seen in the SpongeBob character Sandy Cheeks, the squirrel scientist. Sandy is the only character that comes from the surface (Texas), and she wears a special suit, similar to a radiation suit, and draws from an oxygen source to survive on Bikini Bottom. Affixed to Sandy's suit is a logo that mimics the radiation symbol found on suits used by US government or scientific authorities. Sandy possesses extensive scientific knowledge, not unlike the multitude of US government scientists who see Bikini Atoll as a gold mine of data or as an ideal laboratory to study the impacts of radiation on the terrestrial, marine, and human environments, as well as to advance the careers of Western scientists. 
SpongeBob imitates life, as scientific knowledge and any understanding of the weird and corrosive impacts of radiation come from the outside, like Sandy, thereby perpetuating the idea that the ability to interpret, explain, and create solutions for Bikini Bottom comes from the continental United States. Unlike the character of Sandy, however, the US scientists studying the impacts of nuclear weapons in the Marshall Islands are overwhelmingly represented by white men who exert patriarchal control of radiation narratives emerging from the islands.

\section{A Gendered, Exclusionary Version of History}

Since the beginning of the US colonial era in the Marshall Islands, men, both American and Marshallese, have largely asserted their primary authority to construct and narrate the history of Bikini Atoll and its people. US military and government leaders during and immediately after World War II were predominantly male, and American anthropologists working for the US government during the trusteeship to research and understand the culture and language of the Marshallese people, like Jack Tobin and Leonard Mason, were predominantly men. Although Marshallese society is matrilineal, the spokespeople for Marshallese families are often men, particularly the few that were given access to adequate educational opportunities in English during the trusteeship. Until very recently, when Dr Hilda Heine became the president of the country and the first Indigenous Pacific Islander woman to be a national leader in Oceania, political leaders in the Marshall Islands have been mostly male, including the elected leaders of Bikini Atoll. Major publications focusing on Bikini and the US nuclear weapons-testing program have been written mostly by men (Kiste I974; Weisgall 1994; Niedenthal 200I, 2013). ${ }^{15}$ These accounts provide critically important information about Bikini and the weapons-testing era, but they do not bring Marshallese women into focus. ${ }^{16}$ Similarly, my own research about nuclear testing in the Marshall Islands, which was guided by male Marshallese leaders, focuses on the hardships experienced by Marshallese women but fails to bring their strengths and contributions to light (Barker 20I3).

Furthering this male-centered history of representation is SpongeBob. With the exception of Sandy Cheeks, created after Nickelodeon suggested to Hillenburg that he needed to add a female character (Beck 20I3), all of the main characters on the show are male. The name "Bob" represents the 
everyday man, a common American male, much like a "Joe." Our gaze into the world of Bikini Bottom, as well as the surface of Bikini, is thus filtered through the activities of men.

Indigenous feminist scholar Lisa Kahaleole Hall examined the intersections of racism, sexism, and violence in colonial contexts and considered how these notions become internalized in Indigenous communities (2008). She paid particular attention to the impacts of erasure and the essential need to raise awareness about the different formats for colonial exclusion experienced by women: "Because colonization relies on forced forgetting and erasure, the need to bring the past forward into our consciousnesses is ongoing. Reconstructing tradition and memory is a vital element of indigenous survival, and there is nothing simple or one-dimensional about the process of reconstruction" (L Hall 2008, 279). Hall suggested that many of the stories excluded or erased from male-narrated versions of history-versions that focus on military and political conquest—are accessible in other forms, such as through the arts. The resilience and strength of women are evident in numerous Marshallese cultural practices, such as storytelling, weaving, dance, music (Schwartz 20I2), and literature like the poetry of Jetñil-Kijiner.

Given the intersections of sexism, colonialism, and militarism at play in the Marshall Islands, it is little wonder that the bikini emerged from this post-World War II era. For Bikinian women, however, the garment both sexualizes and depoliticizes the female body, as Teresia Teaiwa described: "The sexist dynamic the bikini performs-objectification through excessive visibility-inverts the colonial dynamics that have occurred during nuclear testing in the Pacific, that is, objectification by rendering invisible. The bikini bathing suit manifests both a celebration and a forgetting of the nuclear power that strategically and materially marginalizes and erases the living history of Pacific Islanders" (2010, I4). ${ }^{17}$

In Oceania, land is the lifeblood of the people; it is treated as a family member, and it is sacred and represents the living spirits of both the ancestors who took care of it and future generations that will continue the synergistic relationship. For the name of Bikini Atoll, the lifeblood of the people, to become a vehicle for the sexualization and depoliticization of women creates an unprecedented cultural violation. Beaches are often framed as sites of elite mobility and leisure (Thurlow and Jaworski 20I0), and the tourist industry represents islands in the Pacific Ocean as fantasized notions of paradise (Kahn 20II). Thus, the bikini becomes synonymous with the privileges of leisure, health, and wealth (Barker 2015). 
While Bikinian women and their bodies are unseen at Bikini Bottom, their namesake is appropriated by privileged bodies across the globe, as well as the fictional Goo Lagoon beachgoers of SpongeBob and the live-action human tourists portrayed in the 2016 SpongeBob movie.

As Lisa Kahaleole Hall maintained, it is essential to challenge the patriarchy of colonialism and to locate and amplify the ways that Indigenous women in Oceania carry their stories into the present (2008). The stories of Bikinian women have sunk below the surface of our public discourse and awareness; the larger public does not hear those stories or appreciate the strength and resilience of Bikinian women's cultural practices that continue to support their community. Bikinian women never stopped passing along and creating new cultural knowledge, but the Western gaze, including my own, has failed to acknowledge or deem important the contributions of these women.

Only brief accounts of Bikinian women appear in historical documents. Historical and cultural overviews by American men closely connected to the Bikini community chronicle the hardship experienced by the Bikinian people after the US government relocated them to Rongerik Atoll (see Kiste 1974) and then moved the community a second time from Rongerik to Kili, a single island rather than an atoll comprising a vibrant system of islands. ${ }^{18}$

When the limitations of living on a single island constrained the marinebased practices and teachings of the Bikinian community, leaving the people with little to no economic activity to support themselves, it was the ingenuity of the Bikinian women that played a large role in bolstering the community. According to Bikinian elder Rosbi Kilon, when the community was struggling to provide for itself on Kili, seven Bikinian women, including her mother, came together to invent a new weaving design (Kilon and Fakatau 20I7). By working collectively with the few natural resources available on the island, the group designed a new and exquisite handbag, the Kili bag, constructed of woven pandanus on the inside and bright white coconut fibers on the outside. The sturdy quality of the coconut fronds, which provide the structure for coconut leaves to extend from the tree, brought durability and better resilience to water and rain than the pandanus used for most Marshallese weavings. In his I974 monograph, anthropologist Robert C Kiste noted the popularity of the Kili bag and the eagerness of US government administrators to purchase the bags and get them to markets: "A woman's purse of unique design ... dubbed the 'Kili bag,' soon became extremely popular and in 
demand by Americans throughout the entire Trust Territory and Guam" (1974, I33). Although the contributions of Bikinian women have not received the attention they deserve, Kilon said Bikinian women "are still very proud of [the bag] today" (Kilon and Fakatau 20I7). There are now other communities in the Marshall Islands and other parts of Oceania that weave their own versions of the Kili bag, but it "is unique to Bikini even though other weavers try to imitate it. They cannot weave the Kili bag as well as the Bikini” (Kilon and Fakatau 20I7). Bikinian women closely guard the knowledge of how to weave the bags and of the design and construction features that make them authentic - knowledge that the women themselves embody, as the few remaining contemporary Kili bag weavers learned the practice from descendants of the seven original creators (Kilon and Fakatau 2017). The protection of knowledge and embodied weaving practices demonstrates that Bikinian women insist on maintaining and safeguarding the communal resilience passed down from their mothers and grandmothers.

Musicologist Jessica Schwartz emphasized the importance of Marshallese togetherness, or ippān doon, ${ }^{19}$ as a critical survival mechanism for communities impacted by nuclear testing. While she applied this community value of ippān doon to singing, it can also be applied broadly across Marshallese culture, such as to weaving, canoe journeys, fishing, dancing, storytelling, ${ }^{20}$ and house building: "Ippān doon affords customary values of togetherness and conviviality as survival mechanisms. It is predicated on gender complementarity and is the prerequisite for the Marshallese definition of freedom as a collective shared space. Ippān doon affords experiential continuity against linguistic processes of fragmentary procedures such as removal from one's land, segregation in camps and on small islands, medical examinations that depended on isolation of bodily fluids and parts, and cultural debasement, which works at the core of colonial power relations" (Schwartz 20I2, I2). Ippān doon is what the Bikinian women produced through the Kili bag, as it is an empowered response to the community's adversity on Kili Island.

From the time the US government exiled the Bikinians to Kili in the I950s until now, Marshallese elected officials, including presidents, have presented Kili bags to US presidents during visits to the White House and to numerous US government, foreign, and other visitors. When gifted, the bags become not only symbols of respect but also important expressions of the Bikinians' resilience, evidenced in the weaving prowess and cultural practices that continue despite the community's forced diaspora. 
Colonial forces, both those exerted by outside powers as well as internalized forms of colonial violence, as Lisa Kahaleole Hall described (2008), marginalize the presence and contributions of Indigenous Pacific Islander women. These combined hegemonic forces-government, military, mass media, church, and anthropological—have submerged the contributions of Bikinian women below the surface for too long. Like radioactivity, just because we don't see it, that doesn't mean it's not present.

\section{Conclusions}

Did SpongeBob's creators intend to infuse a children's show with racist, violent colonial practices? Perhaps not, but by taking place on Bikini Bottom, the cartoon becomes part of a broader, insidious practice of disappearing Indigenous communities and normalizing the nonsensical settling of a community where it does not belong. We should be uncomfortable with a hamburger-loving American community's occupation of Bikini's lagoon and the ways that it erodes every aspect of sovereignty.

If the fan theory connecting the mutations of the characters in the show to radiation exposure from actual nuclear testing is true, perhaps the American public needs SpongeBob to remain far away. The ability to laugh at live-action detonations, mutant characters, and strange behavior becomes easier if it remains geographically and emotionally distant. When scrutinized, popular culture continues colonial efforts to possess, settle, and claim ownership of Indigenous lands, in this case by portraying Bikini Bottom as a place for fictional American characters to reside. While appearing as an innocuous or even inane form of entertainment for children, SpongeBob-as Smokey Bear did before him-reproduces and normalizes the taking of land, removal of people, and appropriation of language and place.

It is important to situate SpongeBob in its broader historical context in order to understand why the surface of Bikini remains uninhabited both in fiction and in reality. The absence of the Bikinians from their ancestral homeland does not mean that Bikini Atoll is up for grabs and available for others, even fictional characters, to inhabit. The show's episodes constantly submerge the viewer's gaze below Bikini's surface, where the realities of the atoll and the people it belongs to lose visibility. The cartoon's lingering presence on Bikini Bottom particularly impacts the women of Bikini by maintaining a militarized, male-centric view of place. By the same token, the cultural strength and resilience of Bikinian women, 
entrenched in enduring cultural forms such as weaving, is frequently hiding in plain sight to outsiders.

SpongeBob creates an opening for conversation, particularly with young people as the target audience. Adults might try to shelter young people from discussions of grave topics, such as those related to the US nuclear legacy, but given the show's extreme visibility in juxtaposition with acute ignorance of the Bikinian experience, SpongeBob creates an opportunity to bridge this gap. As cartoon characters, SpongeBob and his friends create entry points for educating viewers about the history and lives of the Bikinian people. While the public needs to develop a deeper understanding beyond the cartoon, SpongeBob's presence on Bikini Bottom lays the foundation for introductory conversations about the impacts of colonial militarism and imperialism on Oceania and Indigenous worlds. ${ }^{21}$

Oceanian scholars, such as Keith Camacho, have urged academics and others to explore the "diversity of indigenous women and men, elders and youth, whose long histories of colonialism and resistance in the region, as well as in the diaspora, merit academic recognition and representation" (Camacho 20II, 8). With Camacho's encouragement in mind, students at the University of Washington are working with Marshallese communities in the Seattle area to develop curriculum materials for school-aged children that draw on consumer familiarity with SpongeBob. Pacific Islander students at the University of Washington are also involved in research efforts to understand and document the vital resilience and contributions of Bikinians in the community's diaspora, as evident in their weavings housed at the Burke Museum on the university's campus. Bringing community members and students together to awaken the knowledge and pride embodied in the Oceanian collections at the Burke Museum has the potential to create new narratives about the history, strength, and visibility of the Bikinian people that Diaz and Camacho have called on us to locate and amplify. A critical examination of SpongeBob thus creates new opportunities to unsettle and surface the legacies of colonial violence on Bikini and to involve young people in efforts to reorient our gaze toward the resilience and tenacity of a community that consistently finds ways to endure.

This ARTICle Benefits GReatly from the legacies of scholarship of Vince Diaz and Keith Camacho; my appreciation to both for their detailed comments on an earlier draft, which helped shape this piece. Thank you to the many University 
of Washington students-such as Melaika Andrike, Rachael Tamngin, Desiree Gross, Anna Learn, Katherine Hanford, Caylen Bryant, Fa'aumu Kaimana, and others-who deepened my thinking about this topic. Many thanks as well to Ambassador Gerald Zackios, Harriet Phinney, Lani Kramer, Kristina Stege, Rachel Lynn, David Anitok, Alson Kelen, and Jesse Gasper. I am also extremely grateful to Randizia Crisostomo, the Burke's Community Outreach Coordinator for Oceanic and Asian Ethnology, as well as Sven Haakanson and Maya Sugiyama for ongoing discussions related to this article. Thank you Bill, Caleb, and Lucas for enduring many hours of SpongeBob at home, and thank you to the anonymous reviewers and the exceptional TCP editors, Alexander Mawyer, Candice Steiner, and Zakea Boeger.

\section{Notes}

I Methods for this article included participant observation and interviews with Marshallese community members in the Marshall Islands, Auburn, Washington, and Salem, Oregon, over a period of three years. Much of this research emerges from Marshallese community involvement in developing a portion of an exhibit focusing on nuclear culture at the Burke Museum in Seattle, Washington.

2 Lisa Kahaleole Hall noted that Hawaiian-themed representations, like the pineapple or Hawaiian-shirt motif in SpongeBob, underscore how "Hawaiians have consistently been used to stand in for Pacific Islanders as a whole, to the detriment of both Hawaiians and non-Hawaiian Pacific Islanders whose specificities go unmarked and unaddressed" (2015, 728).

3 The "Micro" in Micronesia describes the smallness of the islands, reflecting a colonial mindset that focuses on the limited land in the northern region of Oceania and that fails to grasp the expansive worldview of the local people (see Hau'ofa 2008).

4 For a wonderful read about the tensions between settler communities on Kwajalein and the local Marshallese population, see Robert Barclay's 2002 novel, Melal: A Novel of the Pacific.

5 US military and government forces exerted their influence by anglicizing the names of the land using the names of American sex symbols from the World War II era. For example, Rita and Laura, villages on Majuro Island in the capitol, are named after Rita Hayworth and Lauren Bacall. Renaming land attenuates local knowledge and ties to place and is a common form of colonial violence across Oceania and other colonized spaces worldwide. In the United States Trust Territory of the Pacific Islands, Chuuk became Truk, Guåhån became Guam, and Pikinni became Bikini, and a host of other names were severed from their historical and linguistic context so they would be easier for colonial tongues to pronounce. 
6 The fact that Marshallese created and distributed legends in the Marshallese language during the trusteeship demonstrates their insistence on pushing back against the colonial violences of the era.

7 See Torres Strait Islander artist Brian Robinson's print "Hunting Danghal," which connects all Oceanic realms: https://shop.kickarts.org.au/products/current -exhibitions-brian-robinson-hunting-dhangal.

8 Schoolchildren at Majuro Cooperative School and Assumption School in Majuro are an exception. Those students engaged in critical dialogue about SpongeBob with Rachel Lynn, Kristina Stege, and myself during events surrounding the I March 2017 remembrance day and national holiday.

9 See two academic articles exploring the educational potential of SpongeBob to engage children in conversations about gender (Pillar 20II) and nutritional health (Piatti-Farnell 20I 5 ).

Io Adam Jonas Horowitz's film includes footage of the exact scene in which a US Navy representative asks the Bikinians for "permission" to use their land to "turn something terrible into something good for mankind."

I I See Machin and Mayr 20 I2.

I 2 From Iep Jaltok: Poems from a Marshallese Daughter by Kathy JetñilKijiner. (C) 2017 The Arizona Board of Regents. Reprinted by permission of the University of Arizona Press.

I 3 The same situation exists for people from the Federated States of Micronesia and the Republic of Palau. Thanks to extensive lobbying by the Marshallese and Micronesian communities in Oregon and Washington State, those two states enacted laws to extend certain health provisions, namely medical insurance, to former members of the United States Trust Territory of the Pacific Islands legally residing in the United States (Washington State Health Care Authority 2018).

I 4 The US government removed the Bikinians a second time after acknowledging that the people ingested more radioactive cesium than any known human population (Jonathan Weisgall, quoted in Horowitz 20II; Barker 2013). Creators of SpongeBob fan theories might note that the residents of Bikini Bottom ingest "Jerktonium"- appearing on the periodic table as "Jt"play on radioactive elements ending in "ium," such as plutonium or cesium. In the case of Bikini Bottom, exposure to Jerktonium turned characters into jerks; in the nonfictional world of Bikini, cesium reacts violently with water and can damage cells significantly. I would venture to say that the Bikinians have their own theories about US government representatives that may have ingested Jerktonium. See Genz 20I8, 9I, for a discussion about the jerks who in 2013 created a Halloween haunted house in Rockville, Maryland, featuring Marshallese zombies that participated in US government-sponsored human radiation experiments. 
I 5 Be sure to see Jack Niedenthal's films featuring Marshallese actors, including leaders from the Bikinian community, and the Marshallese language (eg, Niedenthal and others 20I2). His films demonstrate how the arts can refocus our gaze on the stories and languages often overlooked by the dominant, global culture.

I6 I highly recommend Don't Ever Whisper (Johnson 20I3), a book documenting the strength of Darlene Keju-Johnson, who pushed back against cultural norms facing women in the Marshall Islands to promote youth education and advocacy about health issues related to US nuclear weapons testing.

I7 Teresia Teaiwa passed away in 20I7, and I want to express gratitude and respect for her seminal article on Bikini that continues to challenge me to interrogate the gendered violences of the nuclear era.

I 8 Kili has no lagoon, and the nuclear testing and relocation of the Bikinians disrupted canoe building and navigational practices (Genz 20I8). Waan Aelõñ in Majel, a canoe-building program currently under the strong leadership of Bikinian Alson Kelen, reconnects Marshallese youth to the strengths of their cultural practices. I strongly recommend Genz 20I8, as it shatters dominant narratives that portray the Marshallese primarily as victims of US nuclear weapons testing during the Cold War and, in the process, removes from the Marshallese their agency as strong advocates for their islands and culture. As Genz's research underscores, the cultural practices surrounding canoes are based on ancient knowledge that predates four hundred years of colonial disruptions. By documenting Marshallese efforts to reclaim canoe practices, including the highly scientific realm of wave piloting, Genz demonstrated the powerful role that canoe vitalization plays in giving strength to the Marshallese people as they address contemporary challenges, such as the nuclear legacy and the pernicious impacts of climate change.

I9 See LaBriola 2006 for an important discussion on the centrality of the value of ippān doon in Marshallese culture and life.

20 Storytelling as resilience or resistance can inject Marshallese appreciation for humor into storylines, such as an advertisement for a Bravo shot offered at the airport in Majuro alongside a much larger photograph of the actual detonation. Although Kupferman has maintained that the Bravo shot is presented as uncritical nuclear kitsch (2015), the use of humor, as evident in the drink's name, is an essential Marshallese coping method, providing a creative space for Marshallese to construct their own narratives about the aftermath of the nuclear legacy (Barker 20I3). By creating a drink called the "Bravo shot," they employed "self-mockery [as] a serious weapon of cultural resilience and resistance" (Diaz 2004, I 83). Marshallese humor is an essential aspect of cultural resilience emerging from and connected to colonial violence.

2I Genz and others 2018 is an excellent resource for teaching students about militarism and colonialism in Oceania. 


\section{References}

Ahlgren, Ingrid A

2016 The Meaning of Mo: Place, Power and Taboo in the Marshall Islands. $\mathrm{PhD}$ thesis, The Australian National University.

Arvin, Maile, Eve Tuck, and Angie Morrill

20I3 Decolonizing Feminism: Challenging Connections between Settler Colonialism and Heteropatriarchy. Feminist Formations 25 (I): 8-34.

Barclay, Robert 2002 Melal: A Novel of the Pacific. Honolulu: University of Hawai'i Press. Barker, Holly M

20I3 Bravo for the Marshallese: Regaining Control in a Post-Nuclear, Post-Colonial World. Second edition. Belmont, CA: Wadsworth.

2015 Confronting a Trinity of Institutional Barriers: Denial, Cover-Up, and Secrecy. Oceania 85 (3): 376-389.

2018 SpongeBob's Bikini Bottom Is Based on a Real Life Test Site for Nuclear Weapons. The Conversation, I June. http://theconversation .com/spongebobs-bikini-bottom-is-based-on-a-real-life-test-site-for

Beck, Jerry -nuclear-weapons-96687 [accessed I 2 Dec 2018]

20I3 The SpongeBob SquarePants Experience: A Deep Dive into the World of Bikini Bottom. San Rafael, CA: Insight Editions.

Bradley, Bill

2015 SpongeBob SquarePants Answers 7 Big Questions and Debunks I

Popular Theory. Huffpost Tv, 7 February. http://www.huffingtonpost .com/20I 5/O2/o7/spongebob-squarepants-theory_n_6627556.html [accessed 8 May 20I7]

Camacho, Keith L

20 I Cultures of Commemoration: The Politics of War, Memory, and History in the Mariana Islands. Honolulu: University of Hawai'i Press.

Diaz, Vicente M

200 I Deliberating "Liberation Day": Identity, History, Memory, and War in Guam. In Perilous Memories: The Asia-Pacific War(s), edited by Geoffrey M White, T Fujitani, and Lisa Yoneyama, I 55-180. Durham, NC: Duke University Press.

2002 "Fight Boys, "till the Last ..." : Islandstyle Football and the Remasculinization of Indigeneity in the Militarized American Pacific Islands. In Pacific Diaspora: Island Peoples in the United States and Across the Pacific, edited by Paul Spickard, Joanne L Rondilla, and Debbie Hippolite Wright, I69-I94. Honolulu: University of Hawai'i Press.

2004 "To 'P' or Not to 'P'?”: Marking the Territory Between Pacific Islander and Asian American Studies. Journal of Asian American Studies 7 (3): I $83-208$. 
Dvorak, Greg

201 8 Coral and Concrete: Remembering Kwajalein Atoll Between Japan, America, and the Marshall Islands. Honolulu: University of Hawai'i Press.

Encyclopedia SpongeBobia

2017 Goo Lagoon. http://spongebob.wikia.com/wiki/Goo_Lagoon [accessed I 2 May 20I7]

Erdland, August P

I9I4 Die Marshall-insulaner: Leben und Sitte, Sinn und Religion eines Südsee-Volkes. Münster: Aschendorffsche Verlagsbuchhandlung.

Falgout, Suzanne, Lin Poyer, and Laurence M Carucci

2008 Memories of War: Micronesians in the Pacific War. Honolulu: University of Hawai'i Press.

FrancisDollarHyde

20I2 What "Fan Theories" Have Blown Your Mind with Their Devastating Logic? Reddit, 29 May. https:/www.reddit.com/r/AskReddit/ comments/ubaqq/what_fan_theories_have_blown_your_mind_with _their/c4tyqmol [accessed 8 May 20I7]

Garrett, Jemima

2016 Hilda Heine Elected First Female Pacific Leader as President of Marshall Islands. ABC News, 26 January. http://www.abc.net.au/news/ 20I6-OI-27/hilda-heine-elected-first-ever-female-pacific-leader/ 7II8664 [accessed I 2 May 20I7]

Genz, Joseph H

2018 Breaking the Shell: Voyaging from Nuclear Refugees to People of the Sea in the Marshall Islands. Honolulu: University of Hawai'i Press.

Genz, Joseph, Jerome Aucan, Mark Merrifield, Ben Finney, Korent Joel, and Alson Kelen

2009 Wave Navigation in the Marshall Islands: Comparing Indigenous and Western Knowledge of the Ocean. Oceanography 22 (2): 234245 .

Genz, Joseph H, Noelani Goodyear-Ka‘ōpua, Monica C LaBriola, Alexander Mawyer, Elicita N Morei, and John P Rosa

201 8 Militarism and Nuclear Testing in the Pacific. Volume I of Teaching Oceania Series, edited by Monica C LaBriola. Honolulu: Center for Pacific Islands Studies, University of Hawai'i-Mānoa.

Gideon, Jān Raynard

20I I Ājinkōj Eo. In Reeaar N̄an Kapilōn, revised by Cheta Anien, Saito Aine, and Jerre Bennett, 69-76. Majuro: Instructional Services Center, Marshall Islands Ministry of Education. First published in 1976. Available from http://katakcenter.org/marshallese.html [accessed I 2 May 20I9] 
Giroux, Henry A

2014 The Violence of Organized Forgetting: Thinking Beyond America's Disimagination Machine. San Francisco: City Lights Publishers.

Hall, Lisa Kahaleole

2008 Strategies of Erasure: US Colonialism and Native Hawaiian Feminism. American Quarterly 60 (2): 273-280.

2015 Which of These Things Is Not Like the Other: Hawaiians and Other Pacific Islanders Are Not Asian Americans, and All Pacific Islanders Are Not Hawaiian. American Quarterly 67 (3): 727-747.

Hall, Stuart

2003 The Whites of Their Eyes: Racist Ideologies and the Media. In Gender, Race, and Class in Media: A Text-Reader, edited by Gail Dines and Jean M Humez, 89-93. Second Edition. Thousand Oaks, CA: Sage Publications.

Hau'ofa, Epeli

2008 We Are the Ocean: Selected Works. Honolulu: University of Hawai'i Press.

Herreria, Carla

2017 The Casting of a White Actor As Native Hawaiian Hero Cuts Deeper Than You Think. HuffPost, Io May. http://www.huffingtonpost .com/entry/zach-mcgowan-niihau-hawaiian_us_59I2ac24e4bo5obd ca60a6a6?ncid=engmodushpmg00000003 [accessed I I May 20I7]

Horowitz, Adam Jonas, director

$20 \mathrm{I} \quad$ Nuclear Savage: The Islands of Secret Project 4.I. Documentary, 87 minutes. San Francisco: Primordial Soup Company/Equatorial Films.

Jetn̄il-Kijiner, Kathy

2017 Iep Jāltok: Poems from a Marshallese Daughter. Tucson: University of Arizona Press.

Johnson, Giff

2013 Don't Ever Whisper: Darlene Keju: Pacific Health Pioneer, Champion for Nuclear Survivors. Charleston, sc: CreateSpace Independent Publishing Platform.

Johnston, Barbara Rose, editor

I994 Who Pays the Price?: The Sociocultural Context of Environmental Crisis. Washington, DC: Island Press.

Johnston, Barbara Rose, and Holly M Barker

2008 Consequential Damages of Nuclear War: The Rongelap Report. New York: Routledge.

Juda, Lucky

2016 Interview by Carmen Borja, Burke Museum, Seattle, I March. 
Kahn, Miriam

$20 \mathrm{I}$ Tahiti Beyond the Postcard: Power, Place, and Everyday Life. Seattle: University of Washington Press.

Kauanui, J Kēhaulani

2016 "A Structure, Not an Event": Settler Colonialism and Enduring Indigeneity. Lateral 5.I.

Kellner, Douglas

2003 Cultural Studies, Multiculturalism, and Media Culture. In Gender, Race, and Class in Media: A Text-Reader, edited by Gail Dines and Jean M Humez, 9-20. Second Edition. Thousand Oaks, CA: Sage Publications.

Kilon, Rosbi, and Deborah Kilon Fakatau

20I7 Interview by author, Majuro, Marshall Islands, 2 March.

Kiste, Robert C

I974 The Bikinians: A Study in Forced Migration. Menlo Park, CA: Cummings Publishers.

Kosek, Jake

2006 Understories: The Political Life of Forests in Northern New Mexico.

Durham, NC: Duke University Press.

Kupferman, David W

2015 How "Natives” Drink. Bravo Shots, For Example: Mourning and Nuclear Kitsch. Postmodern Culture 25 (3).

LaBriola, Monica

2006 Iien Ippān Doon (This Time Together): Celebrating Survival in an “Atypical Marshallese Community." MA thesis, University of Hawai'i-Mānoa.

Machin, David, and Andrea Mayr

2012 How to Do Critical Discourse Analysis: A Multimodal Introduction. Thousand Oaks, CA: Sage.

Nader, Laura, and Hugh Gusterson

2007 Nuclear Legacies: Arrogance, Secrecy, Ignorance, Lies, Silence, Suffering, Action. In Half-Lives and Half-Truths: Confronting the Radioactive Legacies of the Cold War, edited by Barbara Rose Johnston, 299-3 I6. Santa Fe, NM: School for Advanced Research Press.

Niedenthal, Jack

200I For the Good of Mankind: A History of the People of Bikini and Their Islands. Second edition. Majuro, Marshall Islands: Micronitor/ Bravo Publishers.

Niedenthal, Jack, and Suzanne Chutaro, directors

2OI2 Ainikien Jidjid ilo Boñ [The Sound of Crickets at Night]. Feature film, 87 minutes. Majuro, Marshall Islands: Microwave Films. 
Piatti-Farnell, Lorna

20I 5 Consumption, Health, and Disposability in SpongeBob SquarePants. Australian Journal of Environmental Education 3 I (I): I32-I45.

Pillar, Analice

20II Cartoon and Gender: Masculinities in SpongeBob. International Journal of Education Through Art 7 (I): 69-79.

Schwartz, Jessica A

2012 A "Voice to Sing": Rongelapese Musical Activism and the Production of Nuclear Knowledge. Music and Politics 6 (I): I-2 I.

Teaiwa, Teresia K

2010 bikinis and other s/pacific n/oceans. In Militarized Currents: Toward a Decolonized Future in Asia and the Pacific, edited by Setsu Shigematsu and Keith L Camacho, I 5-32. Minneapolis: University of Minnesota Press. First published in The Contemporary Pacific 6:87I09.

Thurlow, Crispin, and Adam Jaworski

2010 Tourism Discourse: Language and Global Mobility. New York: Palgrave Macmillan.

Tobin, Jack

2002 Stories from the Marshall Islands: Bwebwenato Jān Aelōn Kein. Honolulu: University of Hawai'i Press.

Veracini, Lorenzo

2010 Settler Colonialism: A Theoretical Overview. New York: Palgrave Macmillan.

Voyles, Traci Brynne

2015 Wastelanding: Legacies of Uranium Mining in Navajo Country. Minneapolis: University of Minnesota Press.

Waller, Vincent, director

2010 SpongeBob SquarePants. Season 7, episode 5, Keep Bikini Bottom Beautiful/A Pal for Gary. Aired 2 January on Nickelodeon.

Washington State Health Care Authority

2018 COFA Islander Health Care. Olympia, wa: Office of Medicaid Eligibility and Policy. Available from https://www.kingcounty.gov/depts/ health/locations/health-insurance/access-and-outreach/ /media/ depts/health/health-insurance/documents/in-service/20 18/COFA -islander-health-care.ashx [accessed I 2 May 20I9]

Weisgall, Jonathan $\mathrm{M}$

I994 Operation Crossroads: The Atomic Tests at Bikini Atoll. Annapolis,

Wolfe, Patrick MD: Naval Institute Press.

2006 Settler Colonialism and the Elimination of the Native. Journal of Genocide Research 8 (4):387-409. 


\section{Abstract}

Billions of people around the globe are well-acquainted with SpongeBob Squarepants and the antics of the title character and his friends on Bikini Bottom. By the same token, there is an absence of public discourse about the whitewashing of violent American military activities through SpongeBob's occupation and reclaiming of the bottom of Bikini Atoll's lagoon. SpongeBob Squarepants and his friends play a role in normalizing the settler colonial takings of Indigenous lands while erasing the ancestral Bikinian people from their nonfictional homeland. This article exposes the complicity of popular culture in maintaining American military hegemonies in Oceania while amplifying the enduring indigeneity (Kauanui 2016) of the Marshallese people, who maintain deeply spiritual and historical connections to land-even land they cannot occupy due to residual radiation contamination from US nuclear weapons testing-through a range of cultural practices, including language, song, and weaving. This article also considers the gendered violence of nuclear colonialism and the resilience of Marshallese women.

KEYWORDs: SpongeBob SquarePants, Bikini Atoll, nuclear weapons, settler colonialism, cultural resilience, popular culture 